\title{
SPONTANEOUS RUPTURE OF THE HEART
}

\author{
BY \\ ARNOLD LEVENE \\ From the Royal Marsden Hospital \\ Received February 5, 1960
}

Since the first mention of spontaneous rupture of the heart in the writings of William Harvey, the topic has retained the interest of both physicians and pathologists, because of its supposed rarity and perhaps also because of its striking features when seen at autopsy. Though Krumbhaar and Crowell (1925) described it as "the event of a lifetime" in the experience of those engaged in the study of morbid anatomy, the condition is common, only appearing rare, because the subjects in whom it is found are just those least likely to have an autopsy performed on them in a teaching or other large hospital. It is one of a number of diseases that are most frequently seen in a public mortuary, because no adequate certification of the cause of death in the sufferers is available.

Very few papers on this topic have been published in Great Britain. In this century, apart from the small, partially documented series of Goodall and Weir (1927) and Beresford and Earl (1930), they consist of case reports only. Since it is proposed to review the significant papers on the subject in a separate communication, it will only be referred to here as it becomes relevant to the various sections. In the present paper fresh data are presented on the incidence of spontaneous rupture of the heart in a North London public mortuary and the autopsy findings in 50 cases are discussed.

Incidence. The autopsy records of University College Hospital and the register of the Coroner for the Northern District of London were consulted and information abstracted. The former provided detailed autopsy findings on a relatively small number of cases relevant to this study, while the latter provided succinct causes of death after the manner of death certification. In both, those cases were selected where it appeared from the report or entry that death was attributable solely to coronary atheroma or one of its consequences: coronary thrombosis, myocardial infarction or fibrosis and so on, including rupture.

The data from University College Hospital are shown in Table I. Included in the 16 cases of rupture are 4 in which it was interventricular: hence a hæmopericardium was only noticed in 12 cases coming to autopsy in 25 years. I excluded the four cases of rupture of the interventricular septum, in order to afford some comparison with the findings derived from the coroner's register,

TABLE I

Analysis of 385 Cases of Fatal Arteriosclerotic Heart Disease from the AUtopsy ReCORdS OF UNIVERSITY COLLEGE HoSPITAL, 1931-1956 $(5 \cdot 5 \%$ of all autopsies)

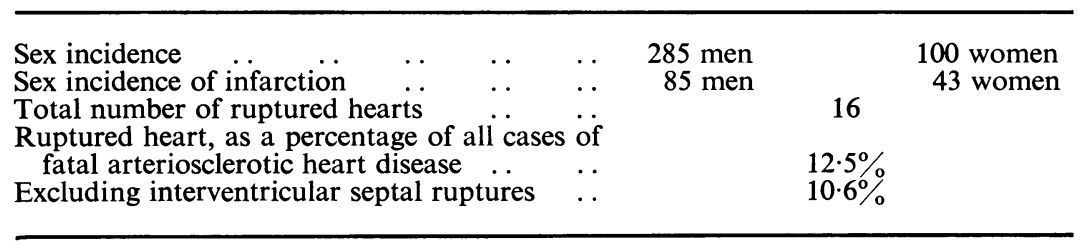


where rupture of the septum is not specifically mentioned. Similarly, except in the case of hæmopericardium associated with rupture, which pathologist and coroner are likely to record as such, the less striking sequelæ of coronary atheroma are only arbitrarily recorded. "Coronary thrombosis" would include cases of myocardial infarction and "coronary occlusion" might include myocardial fibrosis, but this could not be determined from the register. The figure of 12.5 per cent for the incidence of rupture of the heart in a hospital mortuary series of fresh myocardial infarcts, or 10.6 per cent if the interventricular septal group is excluded, corresponds well with the findings of comparable series that Maher et al. (1956) have summarized.

A summary of some data from the Northern District Coroner's Register is given in Table II, from which it can be seen that the number of times that rupture of the heart was seen in men and

TABLE II

ANALYSIS OF 61,090 ENTRIES IN THE ReGISTER OF THE CORONER FOR THE NORTHERN District OF LONDON

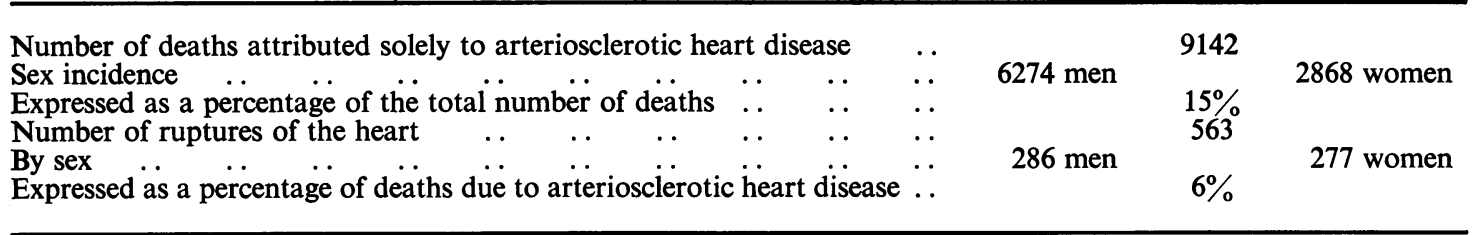

women was almost the same. Yet arteriosclerotic heart disease is generally thought to be more prevalent in men than in women. Thus in the University College Hospital series of autopsies the ratio of men to women dying of this cause was 2.9:1 and in the Public Mortuary series 2.2:1. From the Registrar General's figures it is apparent that this ratio varies with age.

Fig. 1 shows the age distribution of cases of ruptured heart. This and the succeeding graphs are derived from information in the Coroner's Register.

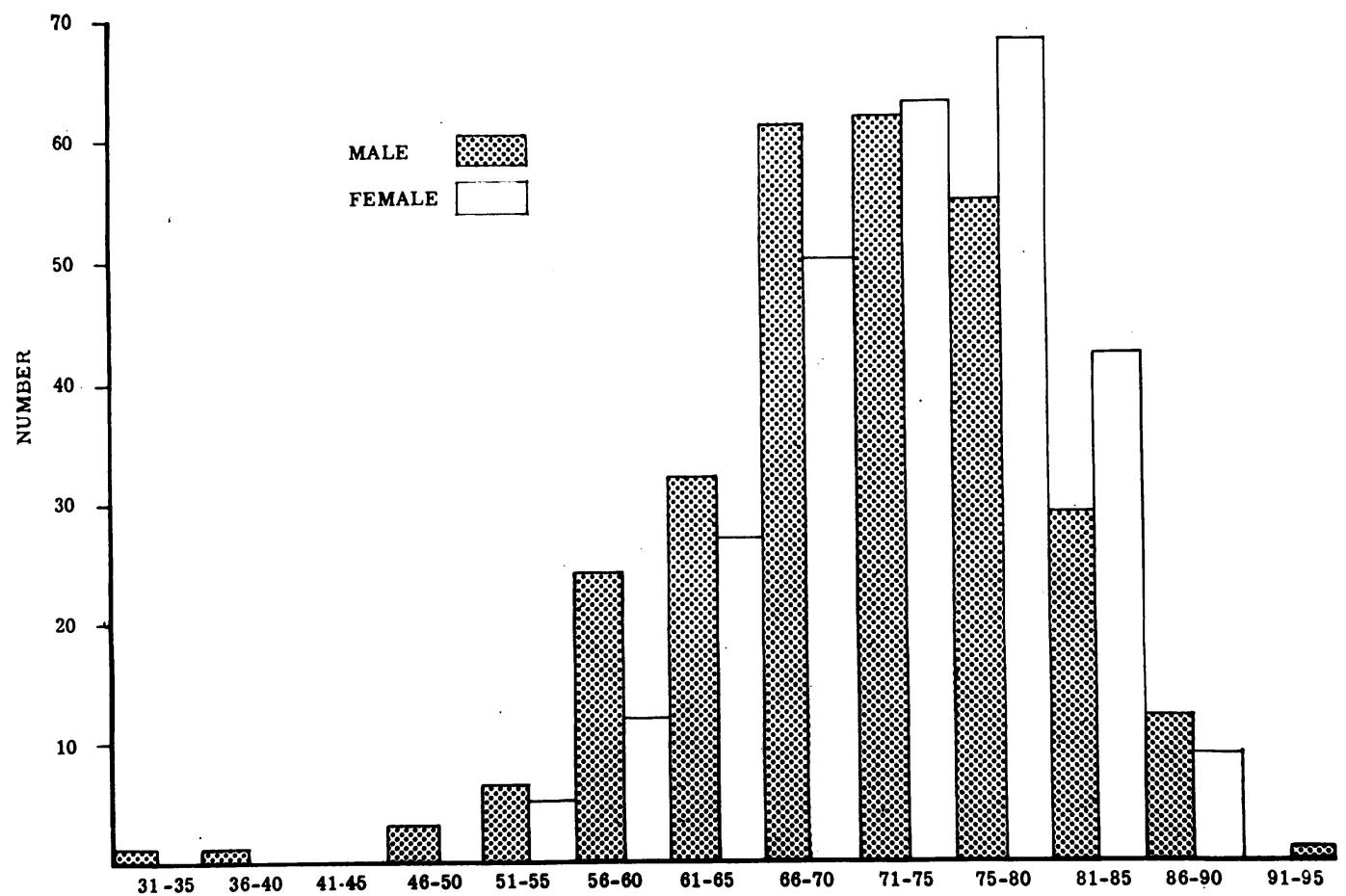

FIG. 1.-The distribution of 563 ruptured hearts according to age. 
From this data it appears that rupture of the heart is seen in equal numbers in the sexes, because it occurs mainly in old age, at which period there is not only a relatively large female population, but also a natural rise in the death rate from arteriosclerotic heart disease in women, the two factors acting together to produce a $1: 1$ ratio. Fig. 2 is another way of looking at this finding. It shows that rupture of the heart is found more often in women dying of arteriosclerotic heart disease than in men.

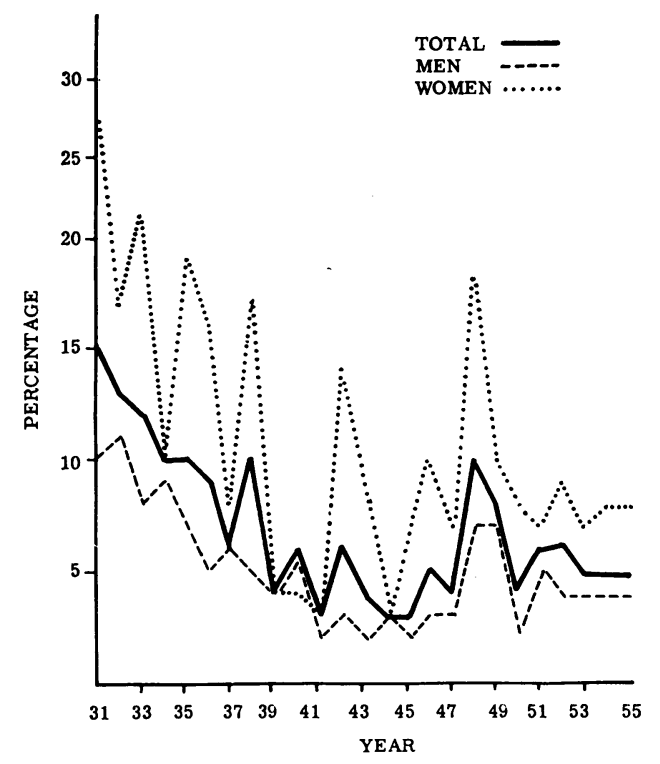

FIG. 2.-The annual variation in the percentage of cases of arteriosclerotic heart disease in which rupture occurs.

This figure also shows an interesting annual fluctuation in the relative incidence of rupture. In the early thirties it was apparently seen about once in every eight cases of arteriosclerotic heart disease and then dropped to about 1 in 20. Since there is no certain knowledge of the populations in which these deaths occurred, one can only speculate on what this drop in the incidence of ruptured heart could mean. It could merely be the result of dilution of an elderly (mortuary) population by more youthful coronary subjects, but the 15 per cent incidence of rupture of the heart in a series of fatal cases of arteriosclerotic heart disease is so high (from the world reports it averages 5 per cent) that it would point to a change in the behaviour of myocardial infarcts during this period. A more likely explanation is that it reflects changing pathological opinion. In the early thirties, coronary atheroma as a cause of death often passed unrecognized, whereas hæmopericardium could not possibly be missed. Levine, writing in 1929, remarked that this common condition still largely passed undiagnosed.

Whether the extent of coronary atheroma present at autopsy is judged sufficient to account for sudden death may be a matter of opinion and experience, and pathologists may differ among themselves. A ruptured heart is unequivocal evidence. I believe that rupture of the heart with hæmopericardium could serve as a check on the accuracy of the post-mortem diagnosis of fatal coronary atheroma, since its apparent incidence would tend to fall where fatal coronary atheroma was overdiagnosed and rise where there was a failure to recognize it. Certainly it is a criterion valid in Britain, which has a large elderly population, but it is unlikely to be of value in countries where life only infrequently extends to 60 and beyond. 
Influence of the Seasons. In Fig. 3 and 4 the seasonal trends of deaths from arteriosclerotic heart disease and rupture of the heart are shown, and they illustrate the well-known inverse relationship between mortality and environmental temperature.

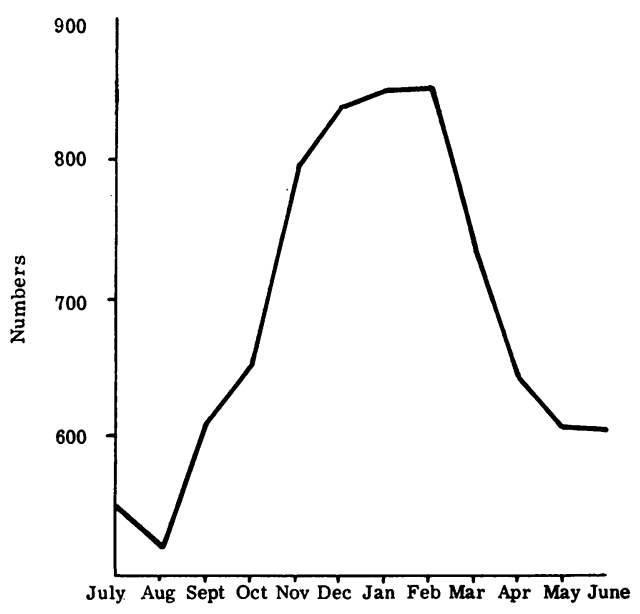

Fig. 3.-The monthly numbers of arteriosclerotic heart deaths in the period 1931-1955, from the register of H.M. Coroner for the Northern District.

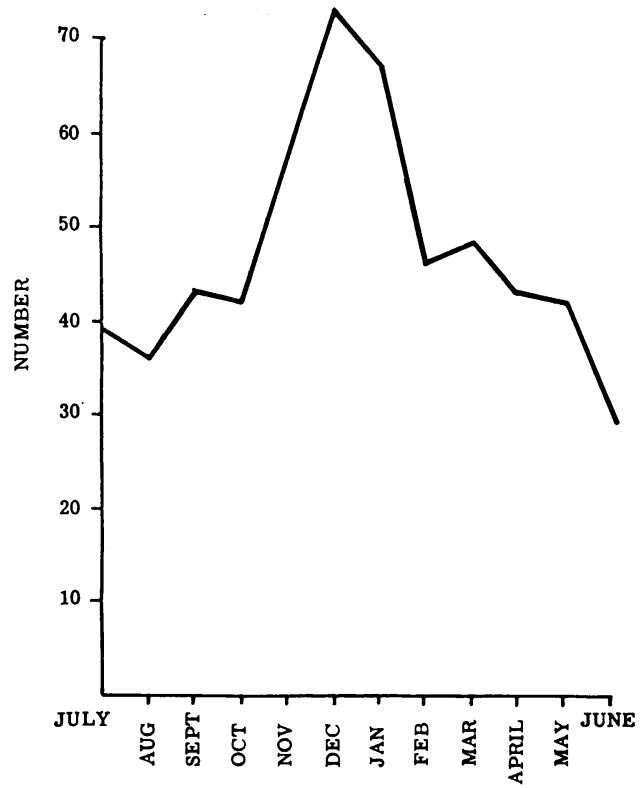

FIG. 4.-The accumulated monthly totals of ruptured hearts in the period 1931-1955.

On the role of environmental temperature in the causation of coronary occlusion and infarction there are broadly three ideas. Cold is a well-known stimulus to peripheral vasoconstriction and may lead to reflex coronary vasoconstriction, and hence to ischæmia. Cold stimulates metabolism and by increasing the work of the heart, unmasks a circulatory inadequacy that was latent. Thirdly, that the work of the heart is increased as a result of acute or chronic respiratory tract disease, which has its peak period in the winter month (see Ministry of Health Reports on Public Health and Medical Subjects, number 95: Mortality and Morbidity during the London Fog of December 1952). This last factor could be of particular importance in the case of older persons, but it is difficult to assess it post mortem.

Clinical Aspects. The histories that relatives give of the events preceding death and the purely medical histories available from the doctor show no significant differences from many cases of myocardial infarction in which no rupture is found. It is exceptional for the patient to be undergoing physical strain in the period associated with the acute symptoms leading to death. This is a fact of some medico-legal importance because cardiac rupture is mainly found in old people, so that, when it occurs in young people, some precipitating factor should be looked for, possibly effort required in the course of their employment (Hallerman, 1938). It was uncommon (only four of my cases) for there to be a previous history of heart disease - a significant point, as will be seen when the purely morbid anatomical aspects are discussed.

The Naked-eye Appearance of Left Ventricular Rupture. With rupture of the ventricle a tense, bluish hæmopericardium is found post mortem, consisting of from a half to one pint of fresh clot. De la Chapelle (1925) found the amount to vary from 200 to $600 \mathrm{ml}$. with an average of $318 \mathrm{ml}$., 
and Munck (1946) found the average to be $380 \mathrm{ml}$. in men and $271 \mathrm{ml}$. in women. The heart, particularly when it is small, may appear to be compressed by the blood. The relative constancy of the size of a hæmopericardium represents the amount necessary to produce death by cardiac tamponade, and accords with similar data obtained from animals (Fineberg, 1936).

In none of my cases of hæmopericardium was an adhesion found attaching visceral to parietal pericardium. Adhesions have been recorded only in hæmopericardium following rupture of cardiac aneurysm. The clot usually falls away from the heart to leave a smooth epicardium but occasionally there is evidence of pericarditis, the clot having to be stripped to expose the left ventricle. Some degree of pericarditis was seen in 6 out of 42 cases that I examined.

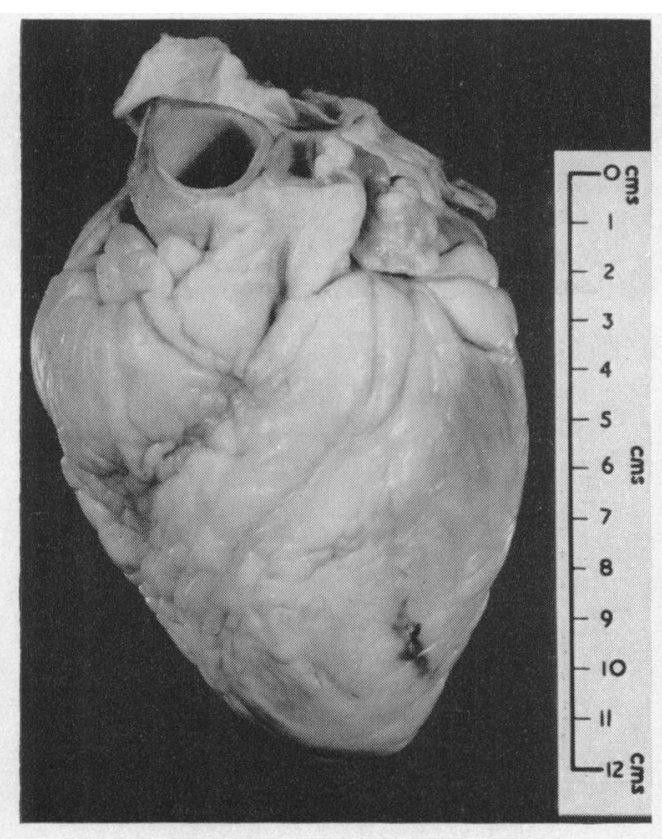

FIG. 5.-Rupture of the heart: small exit tear.

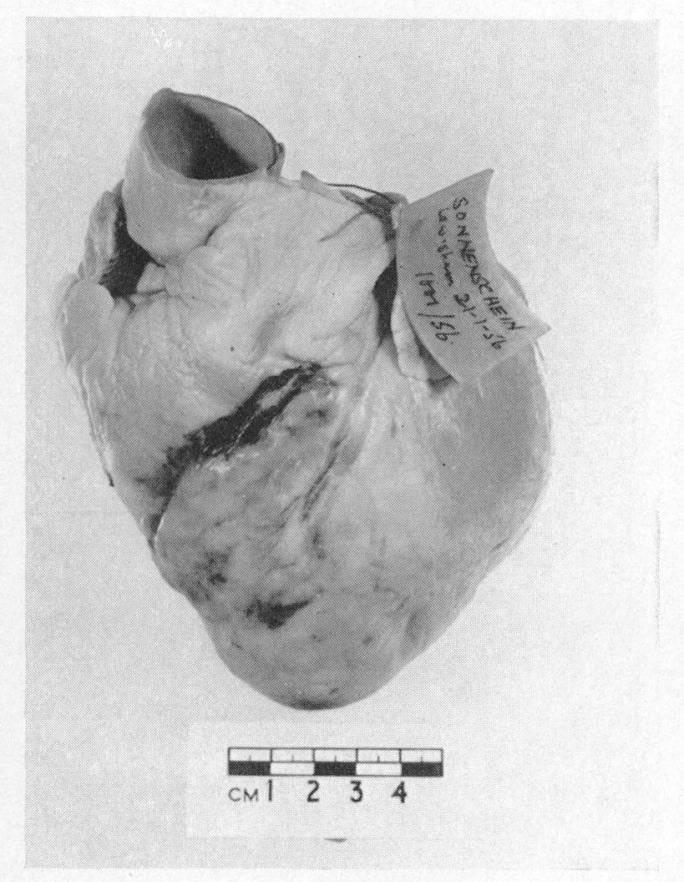

Fig. 6.-Rupture of the heart: gross epicardial infiltration with blood and pericoronary hæmatoma.

The appearance of the tear varies considerably. It may be a barely discernible slit, a few $\mathrm{mm}$. long (Fig. 5), but usually there is some gaping of the epicardium and a variable extravasation of blood into the surrounding epicardial fat (Fig. 6 and 7). Frequently there is extension of the pericardial hæmatoma along the course of the coronary vessels towards the base of the heart (Fig. 8). I measured 25 linear tears and found that the length varied from 3 to $38 \mathrm{~mm}$. with an average of $14 \mathrm{~mm}$. Sometimes two or more tears are seen, but one is the rule. The situation of the tear is related to the area of the infarcted myocardium. I have seen ruptures of left ventricular infarcts only. Certain features of a ruptured heart are best demonstrated on the fresh, unfixed specimen. These include (1) the thrombus adherent to the endocardial surface, (2) the lacerated area underlying the thrombus, which is considerably larger than the tear in the epicardial surface, and (3) the softness of the necrotic muscle through which a finger can be pushed with ease.

The hearts were examined externally, the size and position of the external tear noted, and some attempt made to measure the distance of the middle of this tear from the apex of the heart, but 


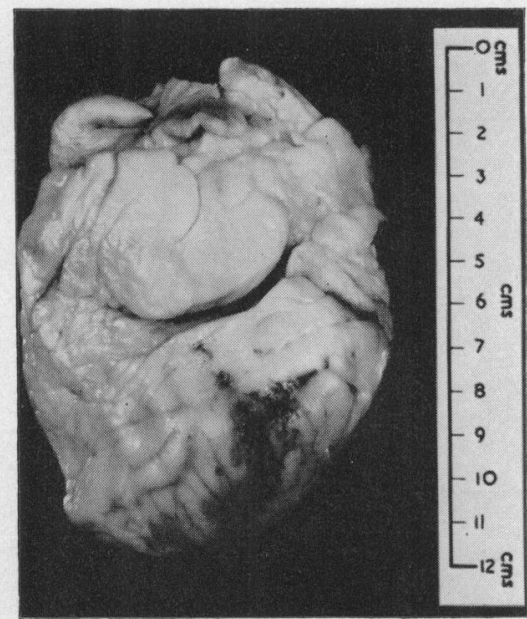

FIG. 7.-Rupture of the heart: moderate epicardial infiltration with blood.

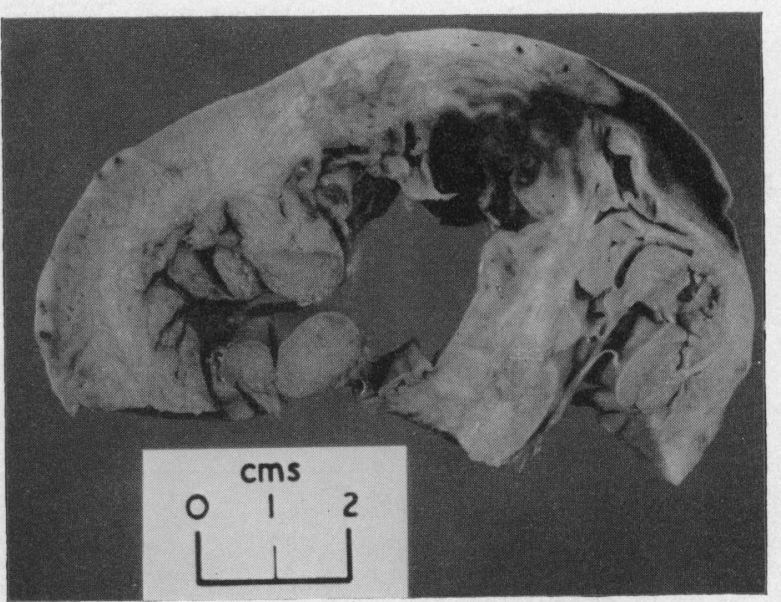

FIG. 8.-The epicardial infiltration seen in transverse section.

since this was often ill-defined, only a rough measurement was possible. The coronary arteries were examined by transverse scalpel cuts (the method suggested by Marie (1896), p. 37 in his thesis) and the heart was then fixed whole in formal-saline.

It was found that transverse sections through the whole heart provided the best method of studying a tear, and this was the method adopted in most cases, although it was modified when required. Drawings, photographs, and histological preparations were made from these slices.

The Coronary Circulation. All the ruptured hearts examined showed severe atheromatous disease of the coronary arteries, usually with an accompanying fresh occlusion in a large branch. It is now accepted that the site of an infarct does not necessarily bear any constant and immediately obvious relationship to the location of the occlusion or occlusions in the coronary arteries (Blumgart et al., 1940). It is clear from Table VI that infarcts that later rupture occur in the same sites and with similar frequency to those that do not.

Using the injection method, Wessler et al. (1952) found old occlusions of the coronary arteries in one-third of ruptured hearts and in three-quarters of non-ruptured controls. Furthermore, fewer intercoronary anastomoses were found in the ruptured hearts compared with controls. This finding is difficult to interpret, especially as argument is still proceeding on the functional significance of anastomoses demonstrated by injection methods. Blumgart et al. (1940) found normal hearts to have anastomoses of up to $40 \mu$ of little functional significance. Obstruction of coronary arteries resulted regularly in the development of inter-coronary anastomoses of 40 to $200 \mu$. This development was not related to age, for example it was not present in senile patients without coronary arteriosclerosis.

It appears, therefore, that hearts with the lesser development of arteriosclerosis, and hence with fewer developed collaterals, are most prone to rupture when infarction occurs. This correlates well with the finding that hearts with evidence of scarring, a consequence of coronary arteriosclerosis, are less liable to rupture than hearts in which scarring is absent (see below).

The Weight of the Heart in Cardiac Rupture. The average weight of the hearts in 18 men was $400 \mathrm{~g}$. and in 24 women $365 \mathrm{~g}$., and the distribution is shown in Table III.

The figures for the weights of a comparable series of arteriosclerotic hearts were obtained from the University College Hospital series, which has been broken down into those cases showing fresh infarction and therefore a group having the special risk of rupture, and those showing a normal or scarred myocardium only (Table IV). 
TABLE III

The Weight of The Heart in 42 CASES OF SPONTANEOUS RUPTURE

\begin{tabular}{c|c}
\hline Weight in grams & Number of cases \\
\hline $201-250$ & 2 \\
$251-300$ & 4 \\
$301-350$ & 10 \\
$351-400$ & 14 \\
$401-450$ & 4 \\
$451-500$ & 6 \\
$501-550$ & 1 \\
$551-600$ & - \\
$601-650$ & 1 \\
\hline
\end{tabular}

TABLE IV

The Comparative Weights of Arteriosclerotic Hearts, With AND WITHOUT INFARCTION

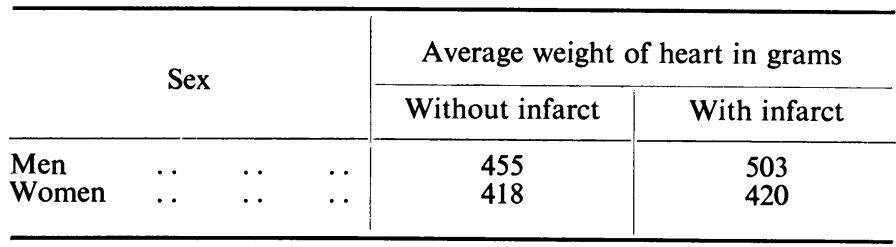

We know from the clinical histories of the patients with ruptured heart that it is exceptional for them to have suffered from previous cardiac symptoms, and the average weight of the hearts indicates that there is no significant degree of left ventricular hypertrophy present. Nevertheless it is clear that cases of arteriosclerotic heart disease in hospital have much heavier hearts, particularly men with fresh or recent infarcts. The hospital series, of course, includes cases of chronic heart failure and those with severe hypertension, conditions well known to be associated with increase of the heart weight.

These findings are of interest in relation to the parallel work of Edmondson and Hoxie (1942) who studied the relationship of hypertension to cardiac rupture and came to the following conclusions. First, patients with persistent hypertension after infarction are three times more likely to develop rupture than those with normal or subnormal blood pressure. Secondly, hearts of normal weight in patients whose hypertension persists after infarction are most likely to rupture. Thirdly, hypertrophied hearts in patients with normal or low blood pressure after infarction are least likely to rupture.

On the other hand Lunseth and Ruwaldt (1956), in a study of the pathogenesis of cardiac rupture due to myocardial infarction, found no elevation of the blood pressure in their cases, in agreement with the earlier findings of Bean (1940). These contradictory opinions may perhaps be resolved along the following lines. There is a rise in the systolic blood pressure with age, long accepted by physicians and life assurance assessors as being a normal event. Furthermore, the rise in systolic pressure with age is not associated with increase of heart weight-the reverse is often seen, as for example in the brown atrophy of the myocardium. From my data and from the opinions of the authorities quoted, it seems reasonable to suggest that rupture of a myocardial infarct occurs principally in old age because of two factors the simultaneous presence of which favours rupture, i.e. hypertension and the absence of left ventricular hypertrophy. Surprisingly Wessler et al. (1952) found no difference in age grouping between their series of patients with ruptured hearts and a control series with myocardial infarction in which rupture was not found at autopsy. 
The Time at which Rupture Occurs. It is now believed that rupture is usually a very early complication of myocardial infarction (Mallory et al., 1939; Lodge-Patch, 1951), and by no means "rare before the fifth day" (Lewis, 1946).

My own findings are summarized in Table $\mathrm{V}$, which records the stage reached without prejudice to the question of the precise age of the infarct. Young granulation tissue probably represents

TABLE V

The Stage OF THE INFARct in 53 Ruptured Hearts

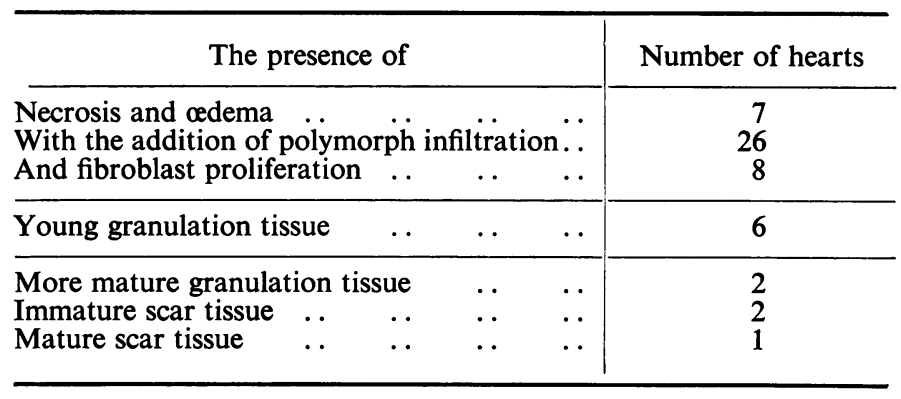

infarcts of approximately one week old. No special histological features of infarction were found to be associated with rupture of the heart.

Myocardial Scarring and its Relation to Cardiac Rupture. In the clinical histories obtainable in my cases of rupture there was no evidence of long-standing heart disease, and 16 of 44 ruptured hearts examined, a little over a third, showed scarring to the naked eye. This was usually in the form of a small focus a few $\mathrm{mm}$. in diameter; occasionally three or four such foci were found. In two cases there was extensive scarring, such as one encounters after occlusion of a major coronary artery, with subsequent total or almost total replacement of the full thickness of the ventricular wall by fibrous tissue. One was a scar $3 \mathrm{~cm}$. in diameter, the other a small saccular aneurysm $2 \mathrm{~cm}$. in diameter.

Of the 14 deaths from a large left ventricular aneurysm recorded in the Public Mortuary series, 4 had ruptured. The rarity of this event is a reflection of the rarity of large cardiac aneurysm, for those predisposed to develop it have had a large infarct that, if it does not prove immediately fatal, will lead to death from heart failure soon after in the vast majority of cases.

Extensive scarring of the heart does not so much protect it from rupture as predispose it to acute heart failure in a subsequent ischæmic attack.

To sum up, gross myocardial scarring without aneurysm formation is never, and aneurysm formation is rarely, associated with myocardial rupture. A minor degree of fibrosis is found in a third of ruptured hearts.

The Topography of Myocardial Ruptures. Infarcts that have ruptured are transmural in the majority of cases. The small lateral wall infarct that has ruptured has no outstanding features (Fig. 9). All that one can observe is a zigzag line through a small area of myocardium, which may or may not show naked-eye evidence of infarction.

With infarcts above $2 \mathrm{~cm}$. in diameter, the rupture usually occurs through or near one edge of the infarcted area. It was uncommon for an infarct of the lateral wall of the left ventricle to rupture in any other way. As a result of oblique tracking through the muscle, the external opening of a tear might be one and a half times the thickness of the ventricular wall away from the internal opening.

With antero-septal infarcts rupture was found to have commenced most frequently where the left ventricular wall becomes continuous with interventricular septum (Fig. 10). The size of the 


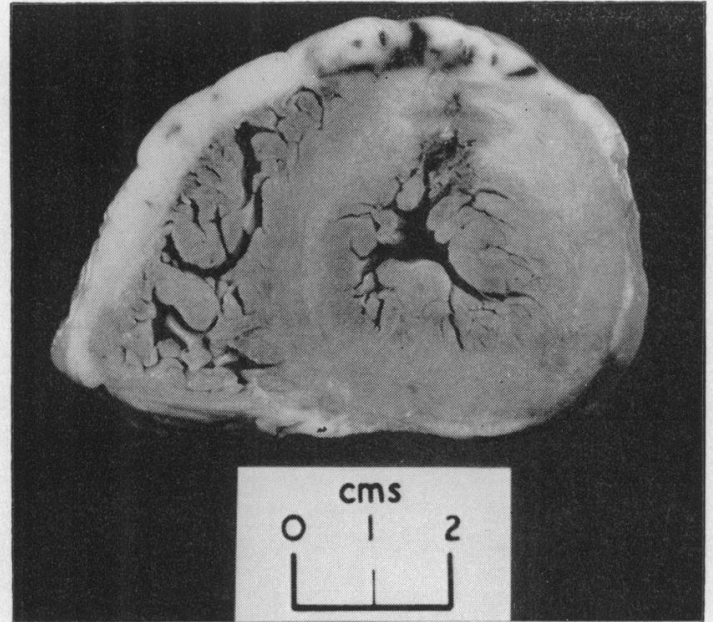

Fig. 9.-Rupture through a small myocardial infarct.

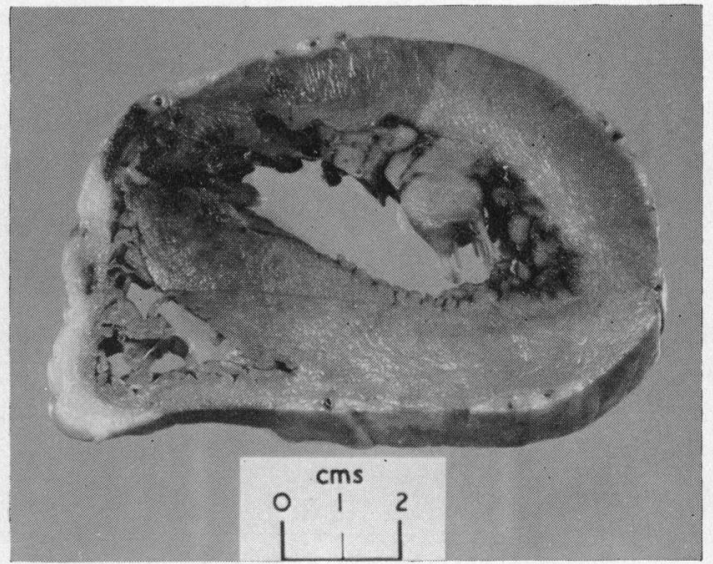

FIG. 10.-Rupture of an antero-septal infarct where the ventricle joins the septum.

infarct was greater than $2 \mathrm{~cm}$. in diameter. Most frequently the rupture appeared in the plane of the anterior projection of the left surface of the interventricular septum. In those cases in which the endocardial tear was succeeded by an oblique track through the musculature, its direction was away from the septum - that is away from the right ventricle. A similar finding was true for postero-septal infarcts.

Some antero- and postero-septal infarcts ruptured either into the right ventricle or behaved as large lateral wall infarcts, the rupture occurring through or near one margin of the infarct laterally (Fig. 11). The frequency of the cases from which the above conclusions were drawn is given in Table VI.

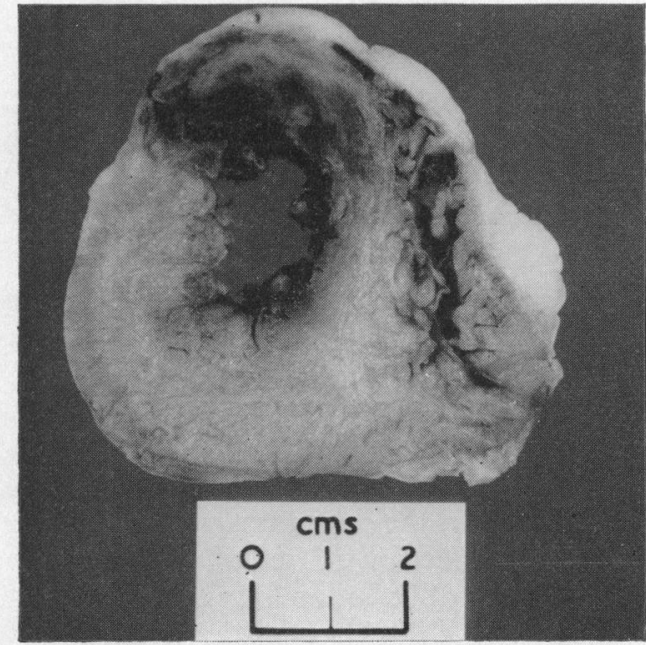

FIG. 11.-Rupture of an infarct of the anterior wall, but with some septal involvement, through the lateral edge of the infarct. 
TABLE VI

The TyPe of CARDIAC RuPture IN 54 Myocardial INFARCTS

\begin{tabular}{|c|c|c|}
\hline & Type of rupture & Number of cases \\
\hline $\begin{array}{l}\text { Antero-septal infarction } . . \\
\text { Antero-septal infarction } . . \\
\text { Antero-septal infarction } \ldots \\
\text { Postero-septal infarction ... } \\
\text { Postero-septal infarction .. } \\
\text { Lateral wall of the left ventricle: } \\
\text { Small or narrow infarct } \\
\text { Large infarct .. . . }\end{array}$ & $\begin{array}{l}\text { Interventricular } \\
\text { Through "ventriculo-septal" angle } \\
\text { Lateral marginal } \\
\text { Through "ventriculo-septal" angle } \\
\text { Lateral marginal } \\
\text { Simple tear } \\
\text { Marginal } \\
\text { Middle }\end{array}$ & $\begin{array}{r}2 \\
19 \\
7 \\
3 \\
1 \\
5 \\
5 \\
14 \\
1\end{array}$ \\
\hline $\begin{array}{l}\text { Apical infarct } \ldots \\
\text { Aneurysm, small saccular }\end{array}$ & $\begin{array}{l}\text { Not classified } \\
\text { Bursting }\end{array}$ & $\begin{array}{l}1 \\
1\end{array}$ \\
\hline
\end{tabular}

Thinning of the left ventricular wall due to infarction was present in less than a third of the cases and was often associated with the presence of fresh laminated thrombus in the shallow endocardial depression. The thrombus was not yet organizing, nor was its ventricular surface smooth, as is the case in established left ventricular aneurysms. Involvement of the Thebesian veins was not conspicuous. I am in agreement with Lunseth and Ruwaldt (1956), who made a systematic search for Thebesian vein thrombosis and concluded that it played no significant role in the pathogenesis of cardiac rupture.

The Factors Affecting Cardiac Rupture. Where a small infarct is present, contraction of the myocardium may pull it apart. This must be an uncommon event, because small myocardial scars following the healing of comparable lesions are common and may even be present in ruptured hearts. In larger infarcts the same disruptive force is operating, but when rupture occurs the appearance suggests that the living muscle has been pulled away from the dead, at least where the endocardial origin of the tear is concerned. Where the strata of the myocardium exert a directing force, blood may burrow from the endocardial side of the rupture between the muscle fibres to appear externally about the middle of the infarct. In the case of antero-septal and postero-septal infarcts, which rupture along the plane of the left surface of the interventricular septum, it appears as if the tearing process began on the endocardial aspect of a separation of the left ventricle and septum. It may be that this angle, when it is formed by non-contractile tissue, is subject to movements and strains, and becomes a special elective site for rupture to occur, and that infarcts elsewhere in the wall are spared.

Tears of the interventricular septum resemble tears of the left ventricular wall in two respects. The tearing process originates on the left ventricular aspect of the septum and, secondly, the appearance of the tear from the right ventricular aspect is like that of the epicardium in a left ventricular rupture. Latham, in 1845, describing the only case of ruptured heart he ever looked after in life, one of interventricular rupture with a large tear in the left side of the septum, remarked: "On the right side it just opened at a point. In truth while we are examining the right side the rupture passed undiscovered." They are rare despite the fact that septal infarction is common. This may be because of support afforded the septum by right ventricular pressure. More important is the blood supply of the septum, which is such that full thickness infarcts are rare. As a result surviving contractile muscle on the right ventricular side (the deep sinospiral) holds the septum together.

Lowe's views on rupture are as follows. If the entire thickness of the ventricular wall is destroyed by infarction then, within some seven to ten days rupture of the wall is likely to occur. At this time owing to autolysis, the infarcted area has lost all tensile strength and has not yet been replaced by maturing fibrous tissue. Rupture may follow infarcts that do not involve the whole thickness of the wall. Analysis of the tensile stresses developed in the remaining normal muscle 
(Lowe and Love, 1948) over an infarct shows that, if the thin layer of superficial muscle alone is left intact, then it may be expected to tear during systole. Further, he noted (Lowe, 1947) that, if an extensive infarct involves the endocardial musculature, tearing along the margin of junction between the infarct and normal tissue may occur, and blood track from the ventricular cavity along the tear. This blood may then dissect along the muscle planes and finally reach the epicardium at the line of junction of the two halves of the superficial muscle sheet. In this case rupture takes place without any tearing of the fibres of the superficial muscle sheet.

Extending his previous studies, Lowe (1941) discussed the consequences of muscle infarction in different parts of the left ventricle. At the apex of the ventricle the whole wall is formed by two superficial muscles, so that destruction of one will lead to great weakening of the wall, whereas destruction of the same muscle bundles at the base will not have such consequences. In the upper two-thirds of the left ventricle the destruction of several of the muscle layers is necessary before rupture can occur.

Whilst agreeing with the bulk of Lowe's opinions, I have not found that dissection in the muscle planes plays a prominent part. The short zigzag perhaps a little obliquely through the myocardium is almost the rule in a rupture. Certainly, I have never observed a long intermuscular hæmorrhagic track. This is not to say that the layers of dead muscle exert no directing effect, for some slight deviation of the track from a plane perpendicular to the endocardium is common. On theoretical grounds too, whether the myocardium is laminated or not, a consideration of the physical principles involved shows that the stress is greatest at the tip of an endocardial fissure and is parallel to the endocardium. Hence a fissure will tend to propagate at right angles to the endocardium, that is along the line of greatest stress.

I wish to thank Dr. F. E. Camps of the London Hospital Medical College, Sir W. Bentley Purchase, Mr. W. H. Heddy, and Mr. S. O. Matthew, Her Majesty's Coroners, and Dr. N. F. C. Gowing, Director of the Morbid Anatomy Department of the Royal Marsden Hospital. Miss June Akister drew the graphs and Mr. Michael Docherty photographed the specimens.

\section{REFERENCES}

Bean, W. B. (1940). Ann. intern. Med., 12, 71.

Beresford, E. H., and Earl, C. J. (1930). Quart. J. Med., 24, 55.

Blumgart, H. L., Schlesinger, M. J., and Davies, D. (1940). Amer. Heart J., 19, 1.

Chapelle, C. E. de la (1925). Amer. Heart J., 1, 315.

Edmondson, H. A., and Hoxie, H. J. (1942). Amer. Heart J., 24, 719.

Fineberg, M. H. (1936). Amer. Heart J., 11, 748.

Goodall, J. S., and Weir, H. B. (1927). Brit. med. J., 1, 834.

Hallerman, W. (1938). Dtsch. Z. des. gerichtl. Medizin., 29, 264

Harvey, W. (1649). The Works of William Harvey. The Sydenham Society, London, 1847, p. 127.

Heberden, W. (1772). Medical Transactions. Royal College of Physicians, London.

Krumbhaar, E. B., and Crowell, C. (1925). Amer. J. med. Sci., 170, 828.

Latham, P. M. (1845). Lectures on Subjects connected with Clinical Medicine comprising Diseases of the Heart, 2 , p. 168. Longmans, Green, London.

Levine, S. A., and Brown, C. L. (1929). Medicine, 8, 245.

Lewis, T. (1946). Diseases of the Heart. 4th ed., Macmillan, London.

Lodge-Patch, I. (1951). Brit. Heart J., 13, 37.

Lowe, T. E. (1939). J. Path. Bact., 49, 195.

- (1940). Med. J. Austral., 1, 826.

- (1941). Amer. Heart J., 21, 326.

- (1941). Med. J. Austral., 1, 693.

-

- (1947). Proc. R. Austral. Coll. Physcns, 2, 75.

—-, and Love, E. R. (1948). Aust. J. exp. Biol. med. Sci., 26, 497.

Lunseth, J. H., and Ruwaldt, Mona (1956). Dis. Chest, 30, 499.

Maher, J. F., Mallory, G. K., and Laurenzi, G. A. (1956). New Engl. J. Med., $255,1$.

Mallory, G. K., White, P. D., and Salcedo-Salgar, J. (1939). Amer. Heart J., 18, 647.

Marie, R. (1896). L'infarctus du Myocarde et ses Conséquences: Rupture, Plaques Fibreuses, Anevrismes du Coeur. G. Carré et C. Naud, Paris.

Munck, W. (1946). Acta path. microbiol. Scand., 23, 107.

Wessler, S., Zoll, P. M., and Schlesinger, M. J. (1952). Circulation, 6, 334. 